\title{
Acquisition of an imitative response in rats'
}

\author{
VAUGHN E. STIMBERT, ROBERT W. SCHAEFFER AND DOUGLAS L. GRIMSLEY
}

FLORIDA STATE UNIVERSITY

Following behavior in rats was tested in an open-field apparatus with four choice-point alternatives. Rats learned to follow leader animals when access to water was contingent on following.

Imitation has been demonstrated to be a learned response by Miller \& Dollard (1941), who showed that rats could learn to follow other rats when reinforcement was made contingent upon following behavior. While there may be some question as to the appropriateness of equating imitation with following behavior, it has been shown repeatedly that rats can be trained to follow one another (Bayroff \& Lard, 1944; Solomon \& Coles, 1954; Church, 1957a, b). All of the preceding studies, however, have used some variation of a $\mathrm{T}$ maze which by virtue of its construction (i.e., the narrow runway and only two choice-point alternatives) facilitates following behavior. The purpose of the present study was to test for following behavior in rats in an apparatus which (1) increased the number of choice-point alternatives over those found in a $T$ maze, and (2) minimized the restrictions which the runway of the $T$ maze places on the animals' movements prior to goal box entrance.

Method

The Ss were 12 male albino rats from the Florida State University colony, about 150 days old at the start of the experiment. They were maintained on ad lib Purina Lab Chow. Prior to training, the Ss were randomly divided into two groups of eight and four animals each. The first group was trained as leaders and the second as followers.

The apparatus shown in Fig. 1 is a multiple-choice maze similar in design to that described by Maier \& Schneirla (1935, p. 459). The maze floor was $1 / 2$ in. plywood and the walls were 3-5/8 in. high. Two starting boxes, each 3 in. wide and 12 in. long, were outfitted with sliding aluminum doors. Four removable double compartment goal boxes were located 12 in. aparton an arc 29 in. from the forward starting gate. Each goal box was divided by $1 / 4$ in. plywood into two compartments 3 in. wide and 12 in. long. The dividers extended to within 3 in. of the entrance door which was 3 in. wide and open to the top of the maze. This arrangement allowed access to either compartment from the main goal box entrance. The interior of the left compartment, utilized by the leader Ss, was white and the right compartment, utilized by the follower Ss, was black. Water $(0.5 \mathrm{ml})$ was presented to the $S$ in a metal cup, $7 / 8$ in. in diameter, through a slot in the back wall of each goal box compartment. A retrace door was used to block the entrance of each goal box to prevent Ss that made an incorrect choice from further exploration of the maze. The start boxes and goal boxes were covered with

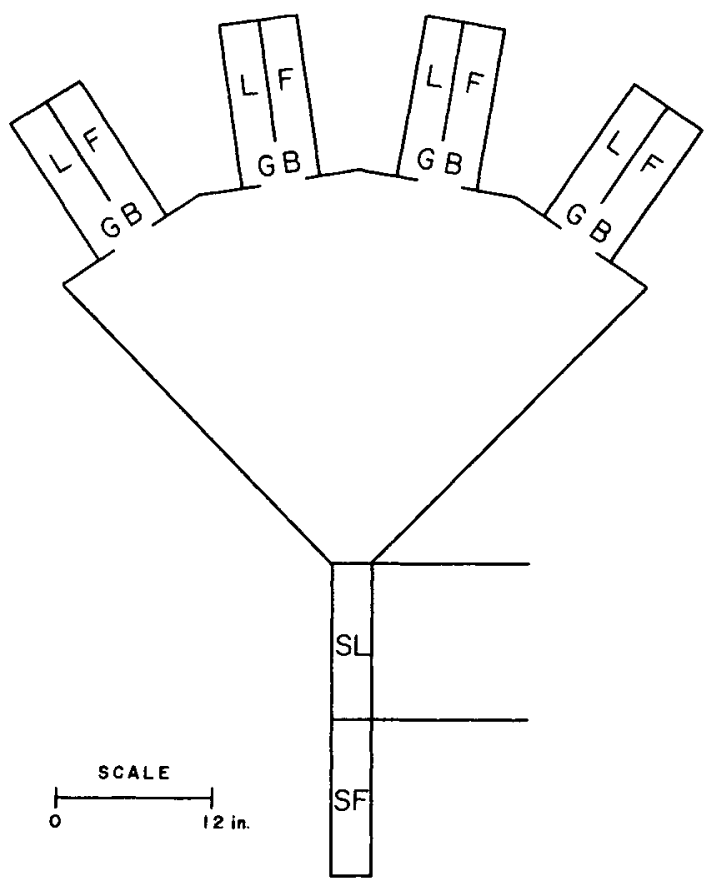

Fig. 1. Diagram of the apparatus. SF, start box for follower Ss; SL, start box for leader Ss; GB, goal box; L, goal box compartment for leader Ss; F, goal box compartment for follower Ss.

hinged Plexiglas tops. The open-field section of the maze was covered with double strength window glass. Except for the goal boxes, the entire maze was painted gray.

The Ss were gentled for seven days and placed on a $22 \mathrm{hr}$. water deprivation schedule. Thirty min. after the completion of each experimental session the Ss were allowed access to water for $30 \mathrm{~min}$.

The eight rats selected as leaders were randomly divided into four subgroups. Each leader $S$ was trained to leave the forward start box and run across the openfield portion of the maze into the left compartment of a specific goal box which contained water. Any S entering an incorrect goal box was retained in the goal box for $30 \mathrm{sec}$, then rerun. In order to habituate the leader Ss to the presence of other Ss in the maze, the leader Ss were then trained to run, in pairs, each to its particular goal box. In this phase of training the leader Ss were alternated between the forward and rear starting boxes on successive training trials.

For one week prior to testing the acquisition of following behavior, follower Ss were given daily access to water in the right compartment of the goal boxes. The subsequent test for following behavior involved the simultaneous release of one leader and one follower 
from the start boxes. Presentation of water was contingent on the follower entering the same goal box as the leader. Entries into an incorrect goal box resulted in retention for $30 \mathrm{sec}$. after which the $S$ was rerun with a new leader. For Ss 4,6 , and 7 , the four goal boxes utilized on successive trials were randomly selected and leader Ss trained to the same goal box were alternated. S 5 was originally run behind leaders trained to the two outside goal boxes. After learning to follow in this two-choice situation, this $S$ was also run behind leaders trained to the inner two goal boxes.

All four follower Ss received 10 massed training trials per day until asymptotic performance, defined as at least 20 consecutive errorless trials, was achieved.

\section{Results and Discussion}

S 5 which originally received training only to the two outermost goal boxes followed on four of the first 10 acquisition trials and reached 100 per cent following on the tenth block of trials. After six errorless sessions were completed, all four of the goal boxes were used. Following was present on the first trial in which the inner two goal boxes were used. In subsequent sessions $S 5^{\prime}$ 's following never dropped below 90 per cent.

Figure 2 shows per cent following for the three Ss run under the four-choice condition over 18 consecutive days. A stable, errorless level of performance was attained in 10,12, and 17 sessions for Ss 7, 4, and 6 respectively.

Errorless performance of the leader Ss is particularly critical in any investigation which employs following behavior as the dependent variable. Five of the eight leader Ss made no errors throughout the entire course of the experiment, in spite of the fact that they were running in close proximity to other Ss who, on occasion, contacted them. The three remaining leader Ss made a total of only 10 errors in the total 890 trials run during acquisition.

A comparison of the results of this study with those of Church (1957a) indicates that increasing the number of response alternatives does not increase the number of trials required to establish errorless following responses. Church's rats required an average of 140

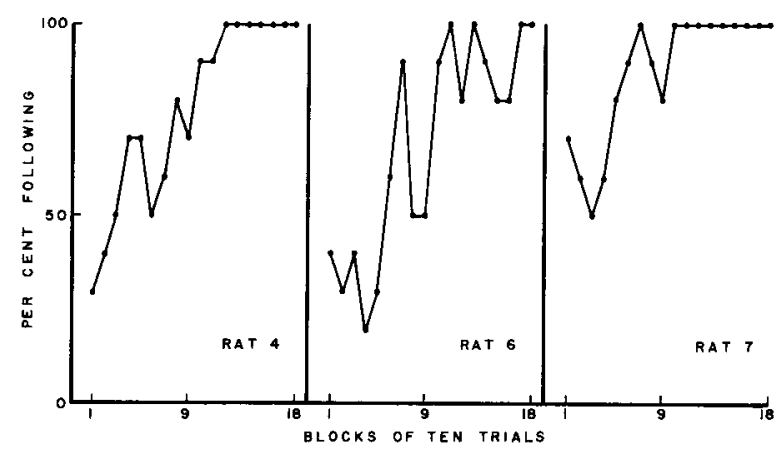

Fig. 2. Per cent following by Ss 4,6 , and 7 as a function of repeated massed testing trials.

trials to reach asymptote in a two-choice situation while those in this experiment reached an equivalent level of following in an average of 130 trials.

The results of this study confirm and extend the findings of previous investigators by demonstrating not only that rats can learn to follow other rats but that rats can learn to follow without error in a relatively "free" environment in which the number of alternatives is twice that found in a $\mathbf{T}$ maze.

\section{References}

Bayroff, A. G., \& Lard, Kathleen E. Experimental social behavior of animals: III. Imitational learning of white rats. J. comp. Psychol., 1944, 37, 165-171.

Church, R. M. Transmission of learned behavior between rats. $J$. abnorm. soc. Psychol., 1957a, 54, 163-165.

Church, R. M. Two procedures for the establishment of "imitative behavior." J. comp. physiol. Psychol., 1957b, 50, 315-318.

Maier, N. R. F., \& Schneirla, T. C. Principles of animal psychology. New York: McGraw-Hill, 1935.

Miller, N. E., \& Dollard, J. Social learning and imitation. New Haven: Yale University Press, 1941.

Solomon, R. L., \& Coles, M. R. A case of failure of generalization of imitation across drives and across situations. J. abnorm. soc. Psychol., 1954, 49, 7-13.

\section{Note}

1. Supported in part by USPHS Grant $\mathrm{MH}-12025$, from the National Institute of Mental Health. 